\title{
Phase I drug-interaction study of effects of calcium and magnesium infusions on oxaliplatin pharmacokinetics and acute neurotoxicity in colorectal cancer patients
}

\author{
Catherine H Han ${ }^{1,2}$, Prashannata Khwaounjoo ${ }^{1}$, Dean H Kilfoyle ${ }^{3}$, Andrew Hill ${ }^{1,2}$ and Mark J McKeage ${ }^{1,2^{*}}$
}

\begin{abstract}
Background: Calcium and magnesium ( $\mathrm{Ca} / \mathrm{Mg})$ infusions have been suggested as an effective intervention for preventing oxaliplatin-induced neurotoxicity, but the effects of $\mathrm{Ca} / \mathrm{Mg}$ infusions on oxaliplatin pharmacokinetics, motor nerve hyperexcitability and acute neurotoxicity symptoms are unclear.
\end{abstract}

Methods: In this double blind crossover study, colorectal cancer patients undergoing oxaliplatin-based chemotherapy were randomised to receive $\mathrm{Ca} / \mathrm{Mg}$ ( $1 \mathrm{~g} \mathrm{Ca}$ Gluconate plus $1 \mathrm{~g} \mathrm{MgSO}_{4}$ ) on cycle 1 and placebo (vehicle alone) on cycle 2 , or to receive the same treatments in the opposite sequence. Study endpoints included plasma pharmacokinetics of intact oxaliplatin and free platinum; electromyography (EMG) detection of abnormal spontaneous high-frequency motor unit action potential discharges; and patient-reported acute neurotoxicity symptoms and their preferred study treatment for reducing these symptoms.

Results: Nineteen of 20 enrolled patients completed the study. Plasma pharmacokinetics of intact oxaliplatin and free platinum were similar when oxaliplatin was given with $\mathrm{Ca} / \mathrm{Mg}$ or placebo (ratio of geometric means of $\mathrm{AUC}_{0-\mathrm{t}}$ with $\mathrm{Ca} / \mathrm{Mg}$ or placebo: intact oxaliplatin, 0.95 ( $90 \% \mathrm{Cl}, 0.90$ - 1.01); free platinum, 0.99 ( $90 \% \mathrm{Cl}, 0.94$ - 1.05)). EMG motor nerve hyperexcitability scores were similar with $\mathrm{Ca} / \mathrm{Mg}$ and placebo (mean difference in EMG score between $\mathrm{Ca} / \mathrm{Mg}$ and placebo: -0.3 (95\% Cl, $-2.2-1.6)$ ). Patient-reported acute neurotoxicity symptoms were similar in frequency with $\mathrm{Ca} / \mathrm{Mg}$ and placebo. For reducing neurotoxic symptoms, fewer patients preferred $\mathrm{Ca} / \mathrm{Mg}$ than placebo or neither treatment $(26 \%$ versus $74 \% ; P<0.01)$.

Conclusions: $\mathrm{Ca} / \mathrm{Mg}$ infusions do not alter the clinical pharmacokinetics of oxaliplatin and do not seem to reduce its acute neurotoxicity.

Trial registration: Trial registration identifier ACTRN12611000738921

Keywords: Oxaliplatin, Calcium and magnesium, Neurotoxicity, Colorectal cancer, Hyperexcitability, Pharmacokinetics, Acute neuropathy

\footnotetext{
* Correspondence: m.mckeage@auckland.ac.nz
'Department of Pharmacology and Clinical Pharmacology and Auckland Cancer Society Research Centre, School of Medical Sciences, Faculty of Medical and Health Sciences, University of Auckland, Auckland, New Zealand ${ }^{2}$ Department of Medical Oncology, Auckland City Hospital, Auckland, New Zealand

Full list of author information is available at the end of the article
} 


\section{Background}

Oxaliplatin-based chemotherapy has become an important treatment for gastrointestinal cancers, including colorectal, esophagogastric and pancreatic cancers [1-8]. In particular, it is a standard therapy for colorectal cancer in both the adjuvant and palliative settings [1,4-7]. Peripheral neurotoxicity is a major dose-limiting toxicity of oxaliplatin, which may compromise the delivery and full therapeutic potential of this drug to achieve tumour control or cure. Acute neurotoxicity occurs in a high proportion of patients shortly after oxaliplatin administration, but may resolve within a few hours or days, and is characterised by cold-related paresthesia, dysesthesia or allodynia, jaw stiffness, and muscle cramps [9]. These acute symptoms may reflect the induction of a state of acute peripheral nerve hyperexcitability detectable on electromyography (EMG) and other neurophysiological studies after oxaliplatin treatment [10-12]. Chronic peripheral sensory neurotoxicity from oxaliplatin can also be troublesome and is characterised by glove-and-stocking paresthesia and dysesthesia, and loss of peripheral deep tendon reflexes, vibration sensation and proprioception [9]. Its recovery after discontinuation of oxaliplatin may be slow, improving gradually over many months or even years, and is incomplete in some patients.

Calcium and magnesium $(\mathrm{Ca} / \mathrm{Mg})$ infusions were adopted by many oncologists in an attempt to reduce oxaliplatin-induced neurotoxicity based on the results of a retrospective analysis by Gamelin et al. [13] and subsequent reports [14]. However, there had been no consensus about the efficacy of $\mathrm{Ca} / \mathrm{Mg}$ infusions for preventing oxaliplatin-induced neurotoxicity, and considerable variation existed in clinical practice with the use of this otherwise simple intervention. The mechanisms of the neuroprotective action of $\mathrm{Ca} / \mathrm{Mg}$ infusions were also unknown. Several mechanisms have been postulated involving sodium or other ion channels [15], but these are unsubstantiated. We hypothesised that $\mathrm{Ca} / \mathrm{Mg}$ infusions could reduce oxaliplatin neurotoxicity by altering the pharmacokinetics of oxaliplatin or by suppressing peripheral nerve hyperexcitability induced by oxaliplatin, possibly via an ion channel mechanism. Recently, we found that the conversion of oxaliplatin to its major degradation product, $\mathrm{Pt}(\mathrm{DACH}) \mathrm{Cl}_{2}$, is accelerated in the presence of calcium or magnesium ions in physiological chloride solutions in vitro, suggesting the potential for a pharmacokinetic interaction to exist between oxaliplatin and $\mathrm{Ca} / \mathrm{Mg}$ infusions in cancer patients [16]. Previously, we had also developed techniques for detecting and measuring oxaliplatin-induced peripheral nerve hyperexcitability in cancer patients based on EMG [10], and for quantitating intact oxaliplatin and free platinum in human plasma samples [17], for application in this study.
In the current cross-over study, we aimed to determine the effect of $\mathrm{Ca} / \mathrm{Mg}$ infusions on the pharmacokinetics of intact oxaliplatin and free platinum in colorectal cancer patients undergoing oxaliplatin-based chemotherapy. Pharmacokinetic studies were carried out on cycles one and two of oxaliplatin treatment using fully validated sample processing and bioanalytical techniques, based on high-performance liquid chromatography (HPLC) and inductively coupled plasma mass spectrometry (ICP$\mathrm{MS})$. The effects of $\mathrm{Ca} / \mathrm{Mg}$ infusions on acute oxaliplatininduced motor nerve hyperexcitability were previously unknown, but objectively evaluated in the current study using EMG techniques. Study patients reported their acute neurotoxicity symptoms and which study treatment they preferred for reducing these symptoms. To reduce bias, patients and researchers, including the neurophysiologist and bioanalyst, were blinded to study treatment details, and the study used a prospective design, placebo control and random assignment of the sequence of study treatments.

\section{Methods \\ Patients}

Eligible subjects were adult patients with colorectal cancer who were to receive standard chemotherapy with an oxaliplatin-based regimen (XELOX or mFOLFOX6) and who had given written informed consent. Subjects with pre-existing peripheral neuropathy, hypercalcemia, hypermagnesemia or medical contraindications to electromyography (EMG) or repeated pharmacokinetic blood sampling were ineligible. The study was approved by the Northern Y Regional Ethics Committee (Approval number NTY/11/01/005).

\section{Design}

This was a prospective, randomised, double-blind, placebocontrolled, cross-over study. Patients were randomly allocated to receive either intravenous $\mathrm{Ca} / \mathrm{Mg}$ (1g calcium gluconate plus $1 \mathrm{~g}$ magnesium sulphate in $100 \mathrm{ml} 5 \%$ dextrose) or placebo (100 $\mathrm{ml} 5 \%$ dextrose) over 15 minutes immediately before and after a two hour oxaliplatin infusion on cycle 1 then crossed over to the other study treatment on cycle 2. Randomisation was carried out by sealed envelope using 1:1 allocation, stratification for oxaliplatin dose $\left(130 \mathrm{mg} / \mathrm{m}^{2}\right.$ versus 85 $\mathrm{mg} / \mathrm{m}^{2}$ ) and a block size of four. Double-blinding was achieved by neither the patients nor any of the research staff knowing the treatment assignment, except an independent oncology nurse who carried out the randomisation, made up the study infusion and recorded the treatment assignment. The active and placebo study treatments were made in identical 5\% dextrose $100 \mathrm{ml}$ infusion bags. Patients received standard 
chemotherapy and supportive care medications according to the standard protocols of our institution.

\section{Endpoints}

The primary endpoint was plasma pharmacokinetic parameters of intact oxaliplatin, including area under the concentration versus time curve from time zero to the last sample $\left(\mathrm{AUC}_{0-\mathrm{t}}\right)$, mean residence time (MRT), clearance $(\mathrm{Cl})$, peak plasma concentration $\left(\mathrm{C}_{\max }\right)$, and volume of distribution at steady state $\left(\mathrm{V}_{\mathrm{ss}}\right)$. The secondary endpoints included free platinum pharmacokinetic parameters, EMG detected abnormal spontaneous highfrequency motor unit action potentials, patient-reported neurotoxicity symptoms and study treatment preference for reducing neurotoxicity symptoms at the end of cycle 2 .

\section{Pharmacokinetic procedures and analysis}

On the day of treatment, blood samples were collected at each of the following time points: pre-infusion; at 20, 40, 60 and 90 minutes after the start of the oxaliplatin infusion; at the end of the infusion and 5, 10, 20, 30, 60, 120 and 180 minutes thereafter. As oxaliplatin is highly unstable in blood and plasma, blood samples were immediately processed to prepare methanol-deproteinised plasma, snap frozen in liquid nitrogen then stored at $-80^{\circ} \mathrm{C}$ until analysis, under which conditions oxaliplatin remains stable [17]. Plasma concentrations of intact oxaliplatin and free platinum were determined by validated HPLC and ICP-MS method [17]. Calibration curve linearity $\left(R^{2}>0.99\right)$, accuracy $(>86 \%)$ and precision $(<13 \%)$, both within and between runs, fulfilled the requirements for validated bioanalytical assays [18]. Pharmacokinetic parameters were calculated using non-compartmental methods and PKSolver [19]. Pharmacokinetic analyses were undertaken with researchers blind to study treatment assignment.

\section{Neurophysiological assessment}

An EMG was performed on day 2 of each study cycle to assess motor nerve hyperexcitability by a neurophysiologist who was blinded to the study treatment assignment. Standard EMG procedures were used and limb temperature was monitored and maintained above $32^{\circ} \mathrm{C}$. EMG was performed in the first dorsal interosseous, extensor digitorum communis, tibialis anterior and gastrocnemius muscles. Motor unit activity was scored as in our previous study [10]:

0 No abnormal motor unit activity

1 increased insertional activity

2 spontaneous high frequency motor unit activity with muscle clinically at rest, with bursts lasting for duration of less than 2 seconds
3 spontaneous high frequency motor unit activity with muscle clinically at rest, with bursts lasting for duration of 2 to 5 seconds

4 spontaneous high frequency motor unit activity with muscle clinically at rest, with bursts lasting for duration of more than 5 seconds.

The final EMG score was calculated as the sum of scores from the four muscles tested on each cycle for each patient (minimum value, 0 ; maximum value, 16 ).

\section{Patient-reported neurotoxicity symptom evaluation}

Patients completed a questionnaire after treatment cycles 1 and 2 to document the presence or absence of acute neurotoxicity symptoms (cold-induced paresthesia, jaw or throat tightness, pain at infusion site, paresthesia unrelated to cold, muscle cramps, change in vision, shortness of breath or other neurotoxicity symptoms). At the end of

\section{Table 1 Baseline clinical characteristics $(n=20)$}

\begin{tabular}{|c|c|c|}
\hline Characteristic & No. of patients & $\%$ \\
\hline \multicolumn{3}{|l|}{ Age, years } \\
\hline Median & 62 & \\
\hline Range & $31-77$ & \\
\hline \multicolumn{3}{|l|}{ Gender } \\
\hline Male & 12 & 60 \\
\hline Female & 8 & 40 \\
\hline \multicolumn{3}{|l|}{ Ethnicity } \\
\hline European & 15 & 75 \\
\hline Maori & 3 & 15 \\
\hline Asian & 2 & 10 \\
\hline \multicolumn{3}{|l|}{$\mathrm{ECOG}^{1}$ status } \\
\hline 0 & 14 & 70 \\
\hline 1 & 6 & 30 \\
\hline \multicolumn{3}{|l|}{ Tumor stage } \\
\hline 2 & 1 & 5 \\
\hline 3 & 11 & 55 \\
\hline 4 & 8 & 40 \\
\hline \multicolumn{3}{|l|}{ Chemotherapy regimen } \\
\hline$X E L O X^{2}$ & 16 & 80 \\
\hline modified FOLFOX $6^{3}$ & 4 & 20 \\
\hline \multicolumn{3}{|c|}{ Neurotoxicity risk factors } \\
\hline None & 17 & 85 \\
\hline Diabetes & 2 & 10 \\
\hline Spinal injury & 1 & 5 \\
\hline \multicolumn{3}{|c|}{$\begin{array}{l}{ }^{1} \text { ECOG, Eastern Cooperative Oncology Group. } \\
{ }^{2} \text { XELOX, 2-hour infusion of oxaliplatin }\left(130 \mathrm{mg} / \mathrm{m}^{2}\right) \text { followed by oral } \\
\text { capecitabine }\left(1250 \mathrm{mg} / \mathrm{m}^{2}\right) \text { twice daily day } 1 \text { to day } 14 \text { every } 3 \text { weeks. } \\
{ }^{3} \text { FOLFOX6, 2-hour infusion of oxaliplatin }\left(85 \mathrm{mg} / \mathrm{m}^{2}\right) \text { together with } 2 \text {-hour } \\
\text { infusion of leucovorin }\left(400 \mathrm{mg} / \mathrm{m}^{2}\right) \text { followed by a fluorouracil bolus } \\
\left(400 \mathrm{mg} / \mathrm{m}^{2}\right) \text { and } 46 \text {-hour infusion }\left(2,400 \mathrm{mg} / \mathrm{m}^{2}\right) \text { every } 2 \text { weeks. }\end{array}$} \\
\hline
\end{tabular}


treatment cycle 2, patients were asked which of the two study treatments given for reducing neurotoxicity they preferred (cycle 1, cycle 2 or no preference).

\section{Statistical analysis}

The statistical analysis of the primary endpoint was carried out in accordance with recommendations for the analysis of drug interaction studies by the US Food and Drug Administration [20]. As recommended, geometric mean and $90 \%$ confidence intervals (CI) of each pharmacokinetic parameter ratio for evaluable patients were calculated. If the $90 \%$ CIs for the geometric mean ratio fell within a no-effect boundary of between $80 \%$ and $125 \%$, then it was to be concluded that there was no significant effect of $\mathrm{Ca} / \mathrm{Mg}$ infusions on the pharmacokinetics of oxaliplatin. No additional dose-normalization was required as each pharmacokinetic parameter for each patient was expressed as ratio of that with $\mathrm{Ca} / \mathrm{Mg}$ infusions versus placebo. Descriptive statistics were used to analyse the EMG data and patient-reported neurotoxicity outcomes. The statistical significance of differences in means and proportions between the placebo and $\mathrm{Ca} / \mathrm{Mg}$ infusion groups were analysed by a paired t-test and Chi-square test, respectively. $P$ values less than 0.05 were regarded as indicating statistical significance.

The study sample size was calculated based on the 90\% CI for the geometric mean ratio of oxaliplatin pharmacokinetic parameters when oxaliplatin is given with and without $\mathrm{Ca} / \mathrm{Mg}$ infusions, and coefficient of variations of oxaliplatin pharmacokinetic parameters of $25 \%$ or less. On this basis, a sample size of 12 evaluable patients was needed to define $90 \%$ CI for pharmacokinetic parameter ratio of \pm 0.12 and for detecting a change in oxaliplatin pharmacokinetics of $25 \%$ or more with statistical significance. To allow for dropouts and discontinuations, a total of 20 patients were planned for enrolment.

\section{Results}

\section{Patients and treatment}

A total of 20 patients were enrolled between June 2011 and July 2012 who were to receive either XELOX (16 patients) or modified FOLFOX6 (4 patients) for colorectal adenocarcinoma. None of the patients had prior chemotherapy or abnormal serum calcium and magnesium levels. Baseline patient characteristics (Table 1) were well balanced between those randomly allocated to receive $\mathrm{Ca} / \mathrm{Mg}$ infusions on the first cycle of chemotherapy then placebo infusion on the second treatment cycle, and those allocated to receive the same study treatments but in the opposite sequence. All patients completed the study except one patient who developed severe chemotherapy related enterocolitis and stopped chemotherapy after cycle one; therefore, this patient was not evaluable (Figure 1). A total of 38 treatment cycles was available for analysis (19 for placebo and 19 for $\mathrm{Ca} / \mathrm{Mg}$ ). All 19 patients completing the study received the same dose of oxaliplatin on both treatment cycles except one patient who had a $10 \%$ dose reduction for cycle 2 due

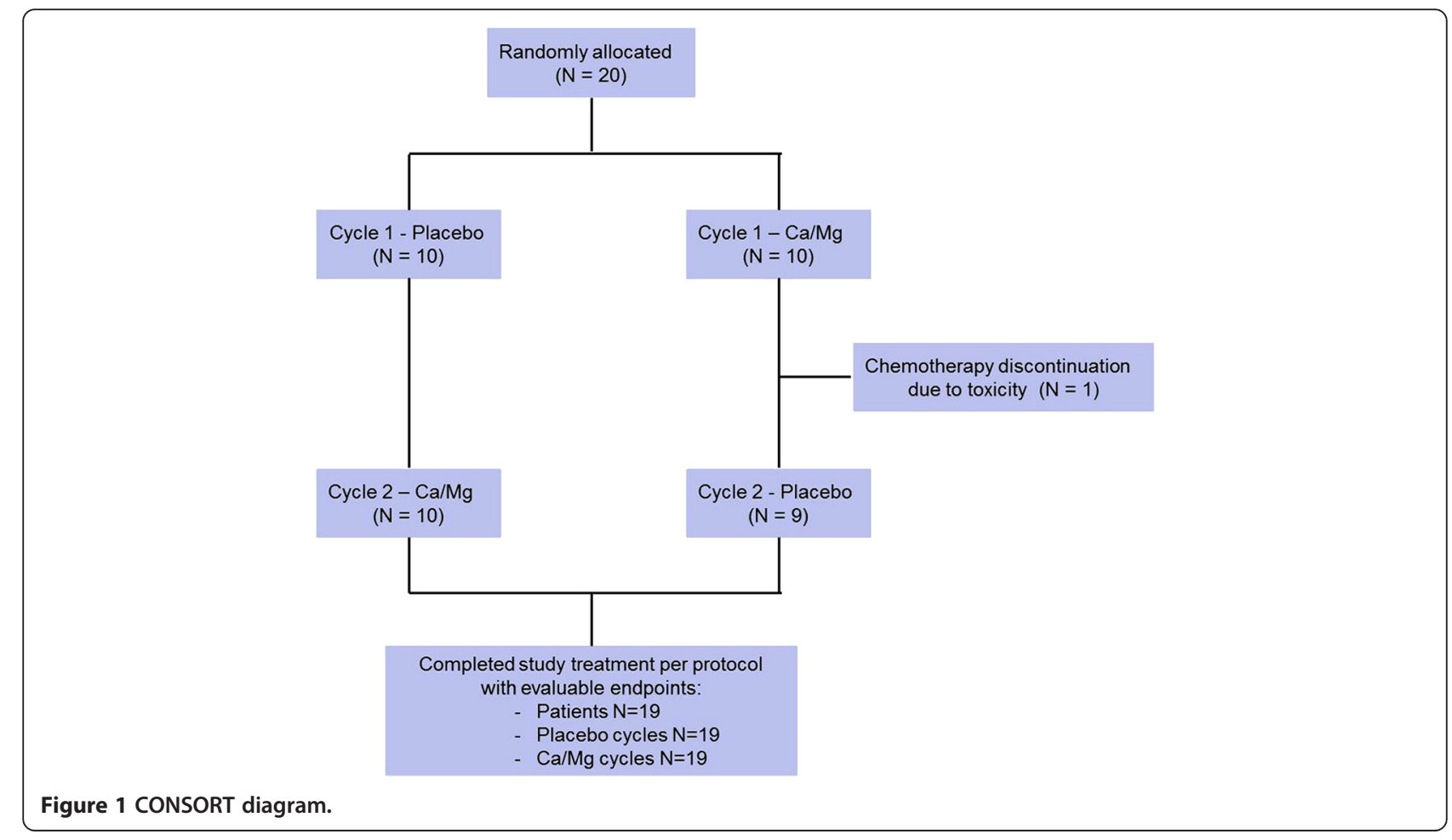


to general intolerance of chemotherapy. There were no adverse effects attributable to the placebo or $\mathrm{Ca} / \mathrm{Mg}$ infusions.

\section{Pharmacokinetics}

Plasma concentrations versus time profiles of intact oxaliplatin (Figure 2A) and free platinum (Figure 2B) were similar when oxaliplatin was given with and without $\mathrm{Ca} / \mathrm{Mg}$ infusions. Plasma concentrations of intact oxaliplatin and free platinum increased during the first hour of the oxaliplatin infusion, plateaued during the second hour, and then decreased rapidly after the end of the oxaliplatin infusion. The plasma concentration values for free platinum appeared to be similar or slightly higher than those for intact oxaliplatin at each time point.

Pharmacokinetic parameters of both intact oxaliplatin and free platinum were similar when oxaliplatin was given with $\mathrm{Ca} / \mathrm{Mg}$ or placebo (Table 2). Ratios of geometric mean values of $\mathrm{AUC}_{0-\mathrm{t}}, \mathrm{C}_{\max }, \mathrm{Cl}, \mathrm{V}_{\mathrm{ss}}$ and $\mathrm{MRT}$ for $\mathrm{Ca} / \mathrm{Mg}$ versus placebo ranged from 0.95 to 1.06 and their respective $90 \%$ CIs fell within the predefined no-effect boundaries of 0.8 to 1.25 . $\mathrm{AUC}_{0-\mathrm{t}}$ values for free platinum were approximately $30 \%$ higher than those for intact oxaliplatin. A subgroup of 15 patients given an oxaliplatin dose of $130 \mathrm{mg} / \mathrm{m}^{2}$, showed similar trends in pharmacokinetic parameter ratios and 90\% CIs compared to the whole group, but their Cmax and $\mathrm{AUC}_{0-\mathrm{t}}$ values for both intact oxaliplatin and free platinum were higher than for those given $85 \mathrm{mg} / \mathrm{m}^{2}$.

\section{Motor nerve hyperexcitability}

EMGs were performed on Day 2 of treatment cycles one and two to assess motor nerve excitability. Abnormal spontaneous high frequency motor unit activity was detected in 19 of 19 patients (100\%) given oxaliplatin with $\mathrm{Ca} / \mathrm{Mg}$ and in 16 of 19 patients (84\%) given oxaliplatin with placebo (Figure 3A). An EMG score was calculated from the severity of motor nerve hyperexcitability and the number of muscles affected. EMG motor nerve hyperexcitability score ranged from zero to 16 in different patient and treatment cycles (Figure 3B). The mean EMG score was 6.5 (SD, 4.31) with $\mathrm{Ca} / \mathrm{Mg}$ and 6.2 (SD, 4.34) with placebo. The mean difference in EMG motor nerve hyperexcitability scores between placebo and $\mathrm{Ca} / \mathrm{Mg}$ infusions for each patient was $-0.3(95 \% \mathrm{CI},-2.2-1.6)$.

\section{Patient-reported acute neurotoxicity symptoms and study treatment preference}

Patient-reported acute neurotoxicity symptoms were similar in frequency when oxaliplatin was given with placebo or $\mathrm{Ca} / \mathrm{Mg}$ infusions (Figure 4A). Cold-induced paresthesia was reported by 16 of 19 patients (84\%) given placebo and 16 of 19 patients $(84 \%)$ given $\mathrm{Ca} / \mathrm{Mg}$ infusions. Jaw or throat tightness was reported by 13 of 19 patients $(68 \%)$ given placebo and 14 of 19 patients (74\%) given $\mathrm{Ca} / \mathrm{Mg}$ infusions. Muscle cramps were reported by 8 of 19 patients (42\%) given placebo and 9 of 19 patients (47\%) given $\mathrm{Ca} / \mathrm{Mg}$ infusions. Few other acute neurotoxicity symptoms were reported. The preferred study treatment selected by patients for reducing neurotoxicity symptoms was placebo in 9 patients (47\%), $\mathrm{Ca} / \mathrm{Mg}$ in 5 patients (26\%), and no preference in 5 patients (26\%) (Figure 4B). Significantly fewer patients preferred $\mathrm{Ca} / \mathrm{Mg}$ infusions for reducing their neurotoxicity symptoms than those who preferred placebo or neither treatment (26\% versus $74 \% ; P=0.01$ ).

\section{Discussion}

The present study is the first, which we are aware of, undertaken to evaluate the effects of $\mathrm{Ca} / \mathrm{Mg}$ infusions

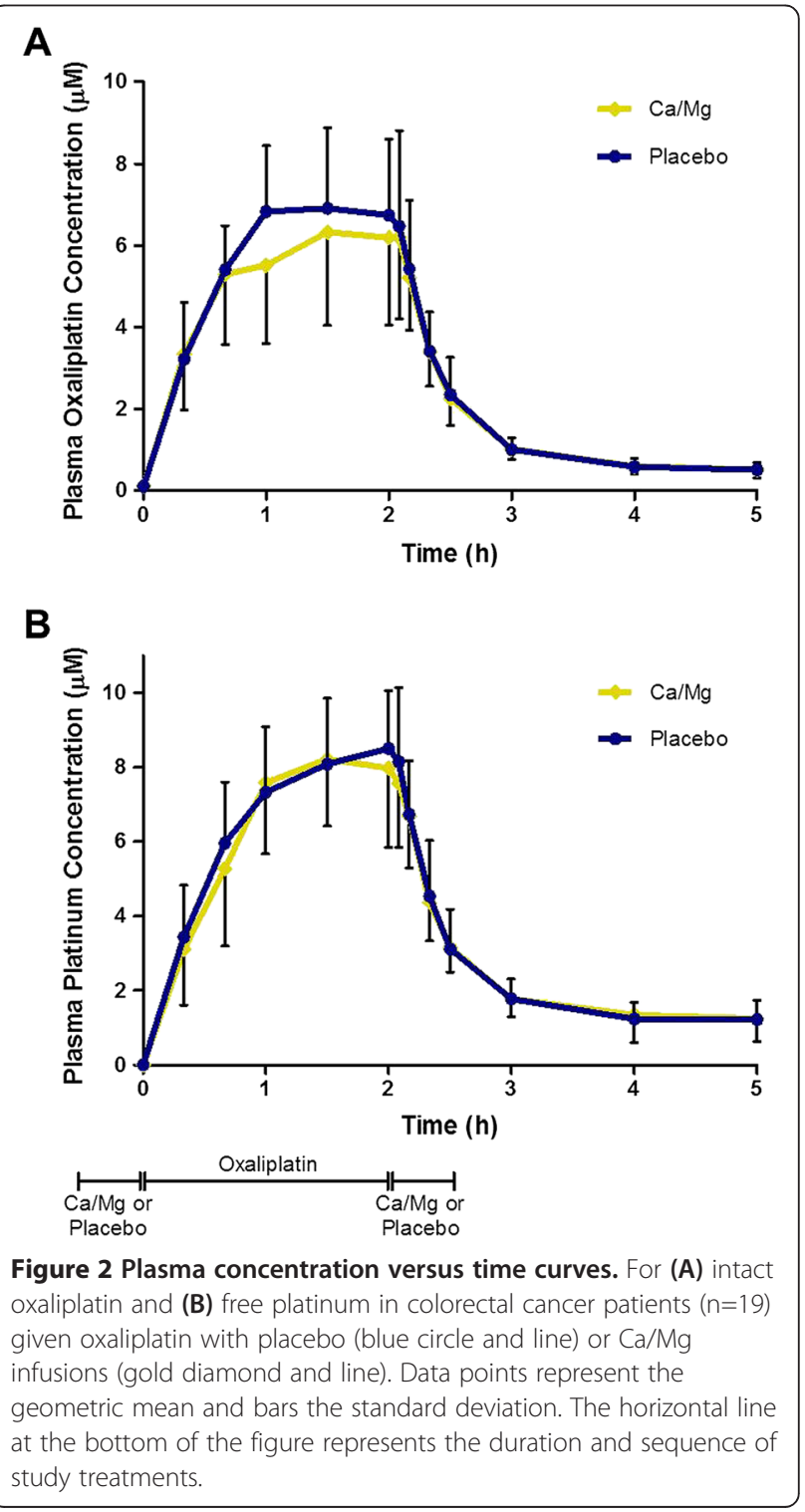


Table 2 Plasma pharmacokinetic parameters of intact oxaliplatin and free platinum in colorectal cancer patients ( $\mathrm{n}=19$ )

\begin{tabular}{|c|c|c|c|c|c|c|c|}
\hline \multirow[b]{2}{*}{ Oxaliplatin dose } & & \multirow[b]{2}{*}{ Study treatment } & \multirow[t]{2}{*}{$\begin{array}{c}\text { AUC }_{0-\mathrm{t}} \\
\left(\mu \mathrm{mol} / \mathrm{L}^{*} \mathrm{~h}\right)\end{array}$} & \multirow[t]{2}{*}{$\begin{array}{c}C_{\max } \\
(\mu \mathrm{mol} / \mathrm{L})\end{array}$} & \multirow[t]{2}{*}{$\begin{array}{c}\mathrm{Cl} \\
(\mathrm{L} / \mathrm{h})\end{array}$} & \multirow[t]{2}{*}{$\begin{array}{l}\mathrm{V}_{\mathrm{ss}} \\
\text { (L) }\end{array}$} & \multirow[t]{2}{*}{$\begin{array}{c}\text { MRT } \\
\text { (h) }\end{array}$} \\
\hline & & & & & & & \\
\hline \multirow[t]{6}{*}{ All $(n=19)$} & Intact oxaliplatin & Placebo & $15.6(3.80)$ & $7.62(1.92)$ & $33.6(7.70)$ & $57.2(15.5)$ & $1.68(0.10)$ \\
\hline & & $\mathrm{Ca} / \mathrm{Mg}$ & 14.8 (3.69) & $7.31(1.91)$ & $35.3(9.76)$ & $59.3(14.9)$ & $1.70(0.13)$ \\
\hline & & Ratio* & $0.95(0.90-1.01)$ & $0.96(0.90-1.02)$ & $1.05(0.99-1.12)$ & $1.06(0.99-1.13)$ & $1.01(0.99-1.04)$ \\
\hline & Free platinum & Placebo & $20.2(4.12)$ & $9.24(1.52)$ & $25.9(6.65)$ & $48.4(11.3)$ & $1.87(0.10)$ \\
\hline & & $\mathrm{Ca} / \mathrm{Mg}$ & $19.8(4.18)$ & $9.52(1.55)$ & $26.8(6.03)$ & $50.9(9.95)$ & $1.90(0.16)$ \\
\hline & & Ratio* & $0.98(0.93-1.03)$ & $1.03(0.95-1.12)$ & $1.04(0.97-1.10)$ & $1.05(0.99-1.12)$ & $1.02(0.99-1.05)$ \\
\hline \multirow[t]{6}{*}{$130 \mathrm{mg} / \mathrm{m}^{2}(\mathrm{n}=15)$} & Intact oxaliplatin & Placebo & $16.9(3.32)$ & $8.28(1.69)$ & $34.5(7.98)$ & $57.3(14.3)$ & $1.66(0.07)$ \\
\hline & & $\mathrm{Ca} / \mathrm{Mg}$ & $15.8(3.51)$ & $8.01(1.63)$ & 36.7 (10.2) & $60.7(17.8)$ & $1.66(0.07)$ \\
\hline & & Ratio* & $0.93(0.86-1.02)$ & $0.97(0.90-1.04)$ & $1.06(0.98-1.15)$ & $1.06(0.98-1.14)$ & $1.00(0.98-1.02)$ \\
\hline & Free platinum & Placebo & 21.8 (3.09) & $9.83(1.06)$ & $26.8(6.57)$ & 49.7 (11.7) & $1.85(0.05)$ \\
\hline & & $\mathrm{Ca} / \mathrm{Mg}$ & $21.3(4.45)$ & $10.0(1.31)$ & $27.8(6.01)$ & $52.2(9.82)$ & $1.88(0.16)$ \\
\hline & & Ratio* & $0.98(0.92-1.04)$ & $1.02(0.94-1.10)$ & $1.04(0.97-1.12)$ & $1.05(0.97-1.14)$ & $1.01(0.98-1.05)$ \\
\hline \multirow[t]{6}{*}{$85 \mathrm{mg} / \mathrm{m}^{2}(\mathrm{n}=4)$} & Intact oxaliplatin & Placebo & $11.4(1.10)$ & $5.58(0.74)$ & 30.7 (6.34) & $53.8(12.5)$ & $1.75(0.18)$ \\
\hline & & $\mathrm{Ca} / \mathrm{Mg}$ & $11.4(1.03)$ & $5.19(0.53)$ & $30.7(5.81)$ & $57.5(10.3)$ & $1.88(0.16)$ \\
\hline & & Ratio* & $1.00(0.82-1.22)$ & $0.93(0.74-1.17)$ & $1.00(0.87-1.15)$ & $1.07(0.88-1.31)$ & $1.07(0.97-1.18)$ \\
\hline & Free platinum & Placebo & $15.3(4.12)$ & $7.32(1.52)$ & $22.9(6.89)$ & $43.9(9.17)$ & $1.92(0.21)$ \\
\hline & & $\mathrm{Ca} / \mathrm{Mg}$ & $15.0(2.79)$ & $7.91(1.35)$ & $23.3(5.17)$ & $46.4(10.4)$ & $1.99(0.17)$ \\
\hline & & Ratio* & $0.98(0.83-1.16)$ & $1.08(0.73-1.60)$ & $1.02(0.86-1.21)$ & $1.06(0.97-1.15)$ & $1.03(0.91-1.17)$ \\
\hline
\end{tabular}

Data values are the geometric mean (standard deviation). Ratio of the geometric mean values for $\mathrm{Ca} / \mathrm{Mg}$ versus placebo were all close to unity and their $90 \% \mathrm{Cls}$ all fell within predefined non-effect boundaries (0.8 to 1.25$)$.

*Ratio of geometric mean $(90 \% \mathrm{Cl})$ : with $\mathrm{Ca} / \mathrm{Mg} /$ with placebo.

Abbreviations: $\mathrm{AUC}_{0-\mathrm{t}}$, area under the curve from time 0 (before oxaliplatin dose) to the last concentration (5 hours from the start of the infusion); $\mathrm{C}_{\text {max }}$ maximum concentration; $\mathrm{Cl}$, clearance; $\mathrm{V}_{\mathrm{ss}}$, volume of distribution at steady state; MRT, mean residence time.

on the pharmacokinetics of intact oxaliplatin and motor nerve hyperexcitability. We showed that $\mathrm{Ca} / \mathrm{Mg}$ infusions do not alter the pharmacokinetics of either intact oxaliplatin or free platinum, and our evidence also indicates that these infusions may provide no benefit in reducing acute oxaliplatin-induced neurotoxicity. The prospective, randomised, double-blind, placebo-controlled design of our study, together with the use of objective and patientreported endpoints of acute neurotoxicity, eliminates potential sources of bias and provides reliable results.
A

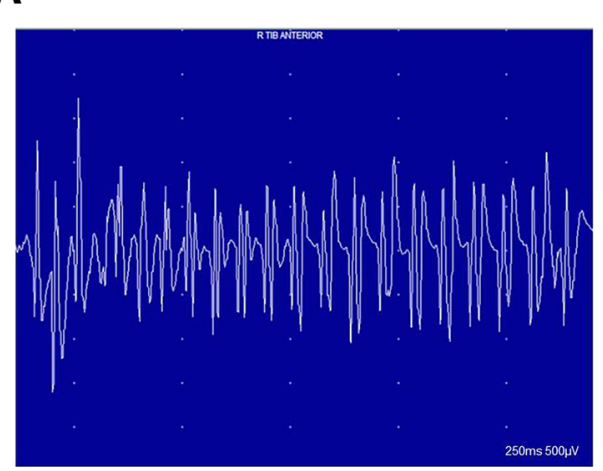

B

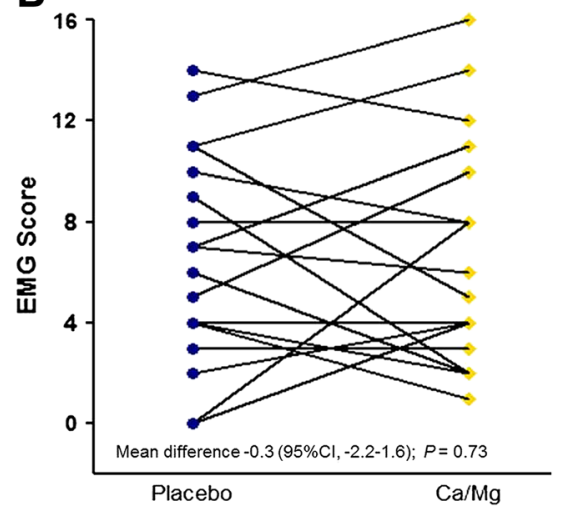

Figure 3 Oxaliplatin-induced motor nerve hyperexcitability. (A) Representative example of abnormal spontaneous high frequency motor unit action potentials detected on electromyography (EMG) on day 2 after oxaliplatin treatment (severity grade 4). (B) EMG motor nerve hyperexcitability score by study treatment on day 2 after treatment cycles one and two given with placebo (blue circle) or Ca/Mg (gold diamond) infusions. Individual scores for each patient are joined by the lines. EMG scores were calculated as described in the methods section. 


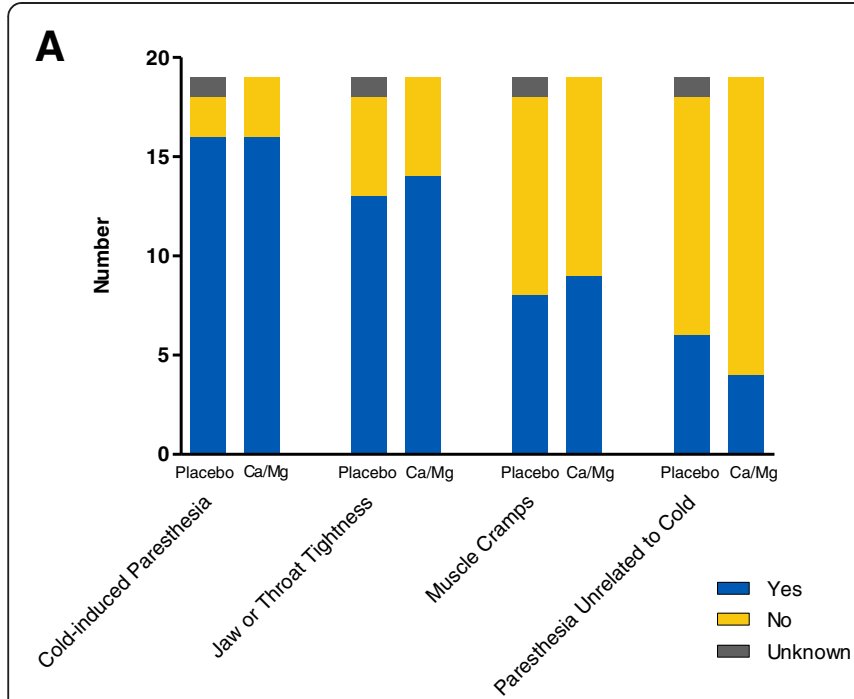

B

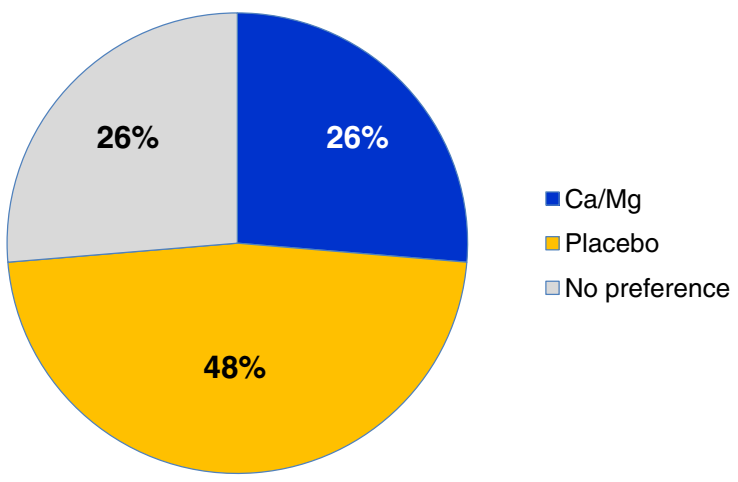

$P(\mathrm{Ca} / \mathrm{Mg}$ vs placebo or no preference $)=0.0096$

Figure 4 Acute neurotoxicity. (A) Patient reported acute neurotoxicity symptoms; and (B) study treatment preferences. The frequency of acute neurotoxicity symptoms was similar when oxaliplatin was given with $\mathrm{Ca} / \mathrm{Mg}$ or placebo infusions. Fewer patients preferred $\mathrm{Ca} / \mathrm{Mg}$ infusions for reducing their neurotoxicity symptoms compared to the number who preferred placebo or had no preference.

We found no evidence of a pharmacokinetic interaction between $\mathrm{Ca} / \mathrm{Mg}$ and oxaliplatin in our study. The plasma concentration versus time profiles and pharmacokinetic parameters of intact oxaliplatin and free platinum were similar when oxaliplatin was given with $\mathrm{Ca} / \mathrm{Mg}$ or placebo infusions. Ratios of their pharmacokinetic parameters were close to unity and their respective $90 \%$ CIs fell within predefined no-effect boundaries of 0.8 and 1.25. We found intact oxaliplatin to be the major platinum species freely circulating in the plasma after oxaliplatin treatment, accounting for approximately $75 \%$ and $80 \%$ of the free platinum $\mathrm{AUC}_{0-\mathrm{t}}$ and $\mathrm{C}_{\text {max }}$, respectively, as previously reported $[17,21]$. The only other study that we are aware of that attempted to compare the plasma pharmacokinetics of platinum in patients given oxaliplatin with or without $\mathrm{Ca} / \mathrm{Mg}$ infusions was reported by Ishibashi et al. [22]. However, the plasma platinum concentration values reported in their study were much lower than expected and over 2000times lower than those from our study. We suspect that loss of platinum analyte due to the instability of oxaliplatin and its reactivity with blood components during the delayed processing of blood samples may have contributed to invalid plasma platinum concentration measurements in their study, although it is not possible to be certain about this.

Most patients in our study demonstrated abnormal spontaneous high-frequency motor unit action potentials on EMGs undertaken about 24 hours after oxaliplatin, as previously reported by our group and others [10-12], but the frequency and severity of these EMG abnormalities did not reduce with the use of $\mathrm{Ca} / \mathrm{Mg}$ infusions. Coinciding with this, similar proportion of patients reported acute neurotoxicity symptoms associated with oxaliplatin between the two treatment cycles given with or without
$\mathrm{Ca} / \mathrm{Mg}$ infusions, and fewer patients preferred $\mathrm{Ca} / \mathrm{Mg}$ infusions than those preferring placebo or neither study treatment. No differences were apparent in EMG scores and patient reported neurotoxicity symptoms between those who received $130 \mathrm{mg} / \mathrm{m}^{2}$ and $85 \mathrm{mg} / \mathrm{m}^{2}$ of oxaliplatin, but this analysis was limited by small sample sizes of these subgroups. Although our study suggests that $\mathrm{Ca} / \mathrm{Mg}$ infusions may have no effect on oxaliplatin neurotoxicity, it showed that repeated EMG assessment of motor hyperexcitability was feasible in patients receiving oxaliplatin chemotherapy. All patients complied with these procedures without loss of data in a total of 38 EMGs, thereby proving objective measurements, which complimented patient-reported endpoints of neurotoxicity. The mechanism of oxaliplatininduced motor nerve hyperexcitability remains unclear but its neurophysiological features are reminiscent of neuromyotonia [12], and may reflect an acute state of generalised peripheral nerve hyperexcitability. If motor and sensory neuropathies are related in this way, future interventions identified to reduce EMG detectable motor nerve hyperexcitability may also have potential for preventing oxaliplatin-induced sensory neurotoxicity.

Our findings disagree with some previous reports regarding the clinical use of $\mathrm{Ca} / \mathrm{Mg}$ infusions with oxaliplatin. A retrospective analysis by Gamelin et al. was the first to suggest that $\mathrm{Ca} / \mathrm{Mg}$ infusions may reduce the neurotoxicity of oxaliplatin [13]. Then several prospective randomised trials $[14,22-24]$ attempted to evaluate the neuroprotective effects of $\mathrm{Ca} / \mathrm{Mg}$ infusions, but all except one trial [18] was prematurely terminated when concerns were raised about lowered tumour responses with $\mathrm{Ca} / \mathrm{Mg}$ infusions. The retrospective design and early closures of subsequent trials may have introduced bias. Evaluation of 
cumulative chronic neurotoxicity of oxaliplatin was not possible in our cross-over study. However, the important question about the efficacy of $\mathrm{Ca} / \mathrm{Mg}$ infusions in preventing chronic oxaliplatin neurotoxicity was addressed by Loprinzi et al. in their large prospective randomised placebo-controlled, double blind trial [25]. They found that $\mathrm{Ca} / \mathrm{Mg}$ infusions do not reduce cumulative neuropathy of oxaliplatin as measured by the sensory scale of the EORTC QLQ-CIPN20 tool. Their findings are complimentary to ours, as both studies, despite their differing methodologies, demonstrated that $\mathrm{Ca} / \mathrm{Mg}$ infusions are not effective in reducing oxaliplatin-induced neuropathy.

Potential limitations of this study include its modest sample size, single centre design and potential for carryover effects. The statistical power of this study was considered a priori when sample size calculations were undertaken using the pharmacokinetics of oxaliplatin as a primary endpoint. Subsequently, actual sample sizes and standard deviations of secondary neurotoxicity endpoints were also used for post-hoc power analyses. These analyses showed that with use of a crossover study design, a sample size of 19 or more evaluable patients has adequate statistical power $(\geq 0.8)$ to detect fairly large but clinically meaningful changes in oxaliplatin pharmacokinetics $(\geq 25 \%)$, EMG motor nerve hyperexcitability score $(\geq 40 \%)$ and in the frequency of cold-induced paresthesia ( $\geq 38 \%$ ), with statistical significance $(\leq 0.05)$. No carry-over effects were evident between cycles one and two in the pharmacokinetics of intact oxaliplatin and free platinum or endpoints of neurotoxicity. Thus, the lack of change found in these endpoints with $\mathrm{Ca} / \mathrm{Mg}$ infusions in the current study might be regarded as true negative findings. This highly efficient and feasible crossover design maybe applied for future initial clinical evaluation of other potentially promising approaches to preventing oxaliplatin neurotoxicity.

\section{Conclusions}

$\mathrm{Ca} / \mathrm{Mg}$ infusions do not alter the clinical pharmacokinetics of oxaliplatin and do not seem to reduce its acute neurotoxicity.

\section{Competing interests}

The authors declare that they have no competing interests.

\section{Authors' contributions}

$\mathrm{CHH}$ coordinated patient recruitment and study procedures, and contributed to the pharmacokinetic sample analysis, data interpretation, statistical analysis and preparation of the final manuscript. PK contributed to pharmacokinetic sample analysis and data interpretation. DHK contributed to the study design and carried out the neurophysiological assessments. AH contributed to the study conception and design. MJM contributed to the study conception, design, data interpretation, statistical analysis and preparation of the final manuscript. All authors read and approved the final manuscript.

\section{Acknowledgements}

We thank the patients, their families, medical oncologists in the gastrointestinal tumour group, research and oncology nursing and administrative staff for their contributions. We also thank the Auckland Medical Research Foundation for research grant support and Health Research Council of New Zealand for a Clinical Research Training Fellowship for Catherine Han.

\section{Author details}

${ }^{1}$ Department of Pharmacology and Clinical Pharmacology and Auckland Cancer Society Research Centre, School of Medical Sciences, Faculty of Medical and Health Sciences, University of Auckland, Auckland, New Zealand. ${ }^{2}$ Department of Medical Oncology, Auckland City Hospital, Auckland, New Zealand. ${ }^{3}$ Department of Neurophysiology, Auckland City Hospital, Auckland, New Zealand.

Received: 1 August 2013 Accepted: 21 October 2013

Published: 25 October 2013

\section{References}

1. Andre T, Boni C, Navarro M, Tabernero J, Hickish T, Topham C, Bonetti A, Clingan P, Bridgewater J, Rivera F, de Gramont A: Improved overall survival with oxaliplatin, fluorouracil, and leucovorin as adjuvant treatment in stage II or III colon cancer in the MOSAIC trial. J Clin Oncol 2009, 27:3109-3116.

2. Conroy T, Desseigne F, Ychou M, Bouche O, Guimbaud R, Becouarn Y, Adenis A, Raoul JL, Gourgou-Bourgade S, de la Fouchardiere C, Bennouna J, Bachet JB, Khemissa-Akouz F, Pere-Verge D, Delbaldo C, Assenat E, Chauffert B, Michel P, Montoto-Grillot C, Ducreux M, Groupe Tumeurs Digestives of U, Intergroup P: FOLFIRINOX versus gemcitabine for metastatic pancreatic cancer. N Engl J Med 2011, 364:1817-1825.

3. Cunningham D, Starling N, Rao S, Iveson T, Nicolson M, Coxon F, Middleton G, Daniel F, Oates J, Norman AR, Upper Gastrointestinal Clinical Studies Group of the National Cancer Research Institute of the United K: Capecitabine and oxaliplatin for advanced esophagogastric cancer. N Engl J Med 2008, 358:36-46.

4. de Gramont A, Figer A, Seymour M, Homerin M, Hmissi A, Cassidy J, Boni C, Cortes-Funes H, Cervantes A, Freyer G, Papamichael D, Le Bail N, Louvet C, Hendler D, de Braud F, Wilson C, Morvan F, Bonetti A: Leucovorin and fluorouracil with or without oxaliplatin as first-line treatment in advanced colorectal cancer. J Clin Oncol 2000, 18:2938-2947.

5. Haller DG, Tabernero J, Maroun J, de Braud F, Price T, Van Cutsem E, Hill M, Gilberg F, Rittweger K, Schmoll HJ: Capecitabine plus oxaliplatin compared with fluorouracil and folinic acid as adjuvant therapy for stage III colon cancer. J Clin Oncol 2011, 29:1465-1471.

6. Kuebler JP, Wieand HS, O'Connell MJ, Smith RE, Colangelo LH, Yothers G, Petrelli NJ, Findlay MP, Seay TE, Atkins JN, Zapas JL, Goodwin JW, Fehrenbacher L, Ramanathan RK, Conley BA, Flynn PJ, Soori G, Colman LK, Levine EA, Lanier KS, Wolmark N: Oxaliplatin combined with weekly bolus fluorouracil and leucovorin as surgical adjuvant chemotherapy for stage II and III colon cancer: results from NSABP C-07. J Clin Oncol 2007, 25:2198-2204.

7. Rothenberg ML, Oza AM, Bigelow RH, Berlin JD, Marshall JL, Ramanathan RK, Hart LL, Gupta S, Garay CA, Burger BG, Le Bail N, Haller DG: Superiority of oxaliplatin and fluorouracil-leucovorin compared with either therapy alone in patients with progressive colorectal cancer after irinotecan and fluorouracil-leucovorin: interim results of a phase III trial. J Clin Oncol 2003, 21:2059-2069.

8. Yothers G, O'Connell MJ, Allegra CJ, Kuebler JP, Colangelo LH, Petrelli NJ Wolmark N: Oxaliplatin as adjuvant therapy for colon cancer: updated results of NSABP C-07 trial, including survival and subset analyses. J Clin Oncol 2011, 29:3768-3774.

9. Grothey A: Oxaliplatin-safety profile: neurotoxicity. Semin Oncol 2003, 30:5-13.

10. Hill A, Bergin P, Hanning F, Thompson P, Findlay M, Damianovich D, McKeage MJ: Detecting acute neurotoxicity during platinum chemotherapy by neurophysiological assessment of motor nerve hyperexcitability. BMC Cancer 2010, 10:451.

11. Lehky TJ, Leonard GD, Wilson RH, Grem JL, Floeter MK: Oxaliplatin-induced neurotoxicity: acute hyperexcitability and chronic neuropathy. Muscle Nerve 2004, 29:387-392.

12. Wilson RH, Lehky T, Thomas RR, Quinn MG, Floeter MK, Grem JL: Acute oxaliplatin-induced peripheral nerve hyperexcitability. J Clin Oncol 2002, 20:1767-1774

13. Gamelin L, Boisdron-Celle M, Delva R, Guerin-Meyer V, Ifrah N, Morel A, Gamelin E: Prevention of oxaliplatin-related neurotoxicity by calcium and 
magnesium infusions: a retrospective study of 161 patients receiving oxaliplatin combined with 5-Fluorouracil and leucovorin for advanced colorectal cancer. Clin Cancer Res 2004, 10:4055-4061.

14. Grothey A, Nikcevich DA, Sloan JA, Kugler JW, Silberstein PT, Dentchev T, Wender DB, Novotny PJ, Chitaley U, Alberts SR, Loprinzi CL: Intravenous calcium and magnesium for oxaliplatin-induced sensory neurotoxicity in adjuvant colon cancer: NCCTG N04C7. J Clin Oncol 2011, 29:421-427.

15. Gamelin E, Gamelin L, Bossi L, Quasthoff S: Clinical aspects and molecular basis of oxaliplatin neurotoxicity: current management and development of preventive measures. Semin Oncol 2002, 29:21-33.

16. Khwaounjoo P: In vitro studies of the effect of calcium and magnesium on the stability of oxaliplatin in chloride solution/Prashannata Khwaounjoo; Thesis (MSc-Biomedical Science) University of Auckland, 2011.

17. Ip V, McKeage MJ, Thompson P, Damianovich D, Findlay M, Liu JJ: Platinum-specific detection and quantification of oxaliplatin and $\mathrm{Pt}(\mathrm{R}, \mathrm{R}$-diaminocyclohexane $) \mathrm{Cl}(2)$ in the blood plasma of colorectal cancer patients. J Anal At Spectrom 2008, 23:881-884

18. U.S. Department of Health and Human Services Food and Drug Administration CfDEaRC: Guidance for Indrustry: Bioanalytical Method Validation; 2001. http://www.fda.gov/downloads/Drugs/ GuidanceComplianceRegulatorylnformation/Guidances/UCM070107.pdf.

19. Zhang Y, Huo M, Zhou J, Xie S: PKSolver: an add-in program for pharmacokinetic and pharmacodynamic data analysis in Microsoft excel. Comput Methods Programs Biomed 2010, 99:306-314.

20. U.S. Department of Health and Human Services Food and Drug Administration CfDEaRC: Drug Interaction Studies —Study Design, Data Analysis, Implications for Dosing, and Labeling Recommendations; 2012. http://www.fda.gov/downloads/ Drugs/GuidanceComplianceRegulatory/nformation/Guidances/ucm292362.pdf.

21. Shord SS, Bernard SA, Lindley C, Blodgett A, Mehta V, Churchel MA, Poole M, Pescatore SL, Luo FR, Chaney SG: Oxaliplatin biotransformation and pharmacokinetics: a pilot study to determine the possible relationship to neurotoxicity. Anticancer Res 2002, 22:2301-2309.

22. Ishibashi K, Okada N, Miyazaki T, Sano M, Ishida H: Effect of calcium and magnesium on neurotoxicity and blood platinum concentrations in patients receiving mFOLFOX6 therapy: a prospective randomized study. Int J Clin Oncol 2010, 15:82-87.

23. Chay WY, Tan SH, Lo YL, Ong SY, Ng HC, Gao F, Koo WH, Choo SP: Use of calcium and magnesium infusions in prevention of oxaliplatin induced sensory neuropathy. Asia Pac J Clin Oncol 2010, 6:270-277.

24. Grothey AHL, Rowland KM, et al: Intermittent Oxaliplatin (oxali) administration and time-to-treatment-failure (TTF) in metastatic colorectal cancer (mCRC): final results of the phase III CONcePT trial. J Clin Oncol 2008, 26:4010.

25. Loprinzi CL, Qin R, Dakhil SR, Fehrenbacher L, Stella PJ, Atherton PJ, Seisler D, Qamar R, Lewis GC, Grothey A: Phase III randomized, placebo (PL)-controlled, double-blind study of intravenous calcium/magnesium (CaMg) to prevent oxaliplatin-induced sensory neurotoxicity (sNT), N08CB: an alliance for clinical trials in oncology study. J Clin Oncol 2013, 31(suppl):3501.

doi:10.1186/1471-2407-13-495

Cite this article as: Han et al.: Phase I drug-interaction study of effects of calcium and magnesium infusions on oxaliplatin pharmacokinetics and acute neurotoxicity in colorectal cancer patients. BMC Cancer 2013 13:495.

\section{Submit your next manuscript to BioMed Central and take full advantage of:}

- Convenient online submission

- Thorough peer review

- No space constraints or color figure charges

- Immediate publication on acceptance

- Inclusion in PubMed, CAS, Scopus and Google Scholar

- Research which is freely available for redistribution 